International Journal of Health Sciences
Available online at www.sciencescholar.us
Vol.5 No.3, December 2021, pages: 617-629
e-ISSN: 2550-696X, p-ISSN: 2550-6978
https://doi.org/10.53730/ijhs.55n3.2681

\title{
The Use of Synchronous and Asynchronous Teaching Methods in Pedagogical Education in COVID-19 Terms
}

\author{
CrossMark \\ Valentyna Lytvyn a, Olena Akimova ${ }^{b}$, Halyna Kuznetsova ${ }^{c}$, Tetiana Zenchenko ${ }^{d}$, Olena Stepanenko ${ }^{\text {e }}$ \\ Inna Koreneva ${ }^{f}$
}

Manuscript submitted: 22 July 2021, Manuscript revised: 07 October 2021, Accepted for publication: 24 November 2021

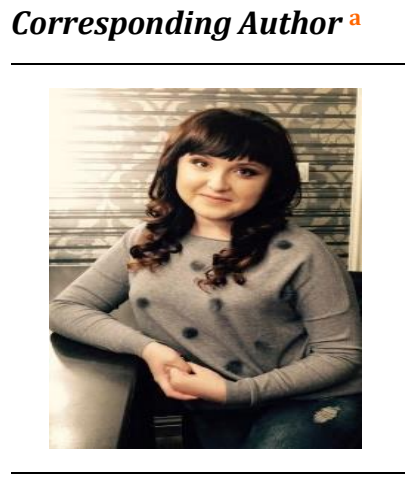

Keywords

COVID-19 terms; educational activities; educational information; educational policies; educational process; higher educational institution; learning conditions; mentoring;

\begin{abstract}
The purpose of the academic paper lies in determining the ratio of synchronous and asynchronous teaching methods in modern pedagogy on the example of the analysis of the activity of higher education institutions within the conditions of quarantine restrictions. The sociological survey was conducted in two stages. Stage I - July - September 2021 (stage of information collection: opinion poll). The second stage is October 2021 (analytical). The advantages of synchronous teaching and learning have been determined, namely: easy interaction; realtime mode; questioning, instant answers, motivation, and help, immediate feedback from the teacher, group classes, high concentration. The disadvantages of synchronous teaching and learning have been identified, namely: physical compliance with the schedule, poor implementation of individualization, appropriate training, poor content of the digital learning platform, poor organization of various communication channels, and low level of digital alternative. The list of benefits of asynchronous learning has been revealed as follows: flexibility, antilocalization, economy, time mobility, one's own working pace, the schedule convenience, point definition of the purposes. It has been found that the drawbacks of asynchronous learning are as follows: a decrease in an academic discipline, a decrease in socialization, feedback difficulty, limited contact, isolation, the need for self-discipline.
\end{abstract}

International Journal of Health Sciences (C) 2021. This is an open access article under the CC BY-NC-ND license (https://creativecommons.org/licenses/by-nc-nd/4.0/).

${ }^{a}$ Kharkiv Humanitarian-Pedagogical Academy of Kharkiv Regional Council, Kharkiv, Ukraine

b Kharkiv Humanitarian-Pedagogical Academy of Kharkiv Regional Council, Kharkiv, Ukraine

c Oleksandr Dovzhenko Hlukhiv National Pedagogical University, Hlukhiv, Ukraine

d Oleksandr Dovzhenko Hlukhiv National Pedagogical University, Hlukhiv, Ukraine

e Communal institution of higher education Dnipro Academy of Continuing Education of Dnipropetrovsk Regional Council, Dnipro, Ukraine

f Kharkiv Humanitarian-Pedagogical Academy of Kharkiv Regional Council, Kharkiv, Ukraine 


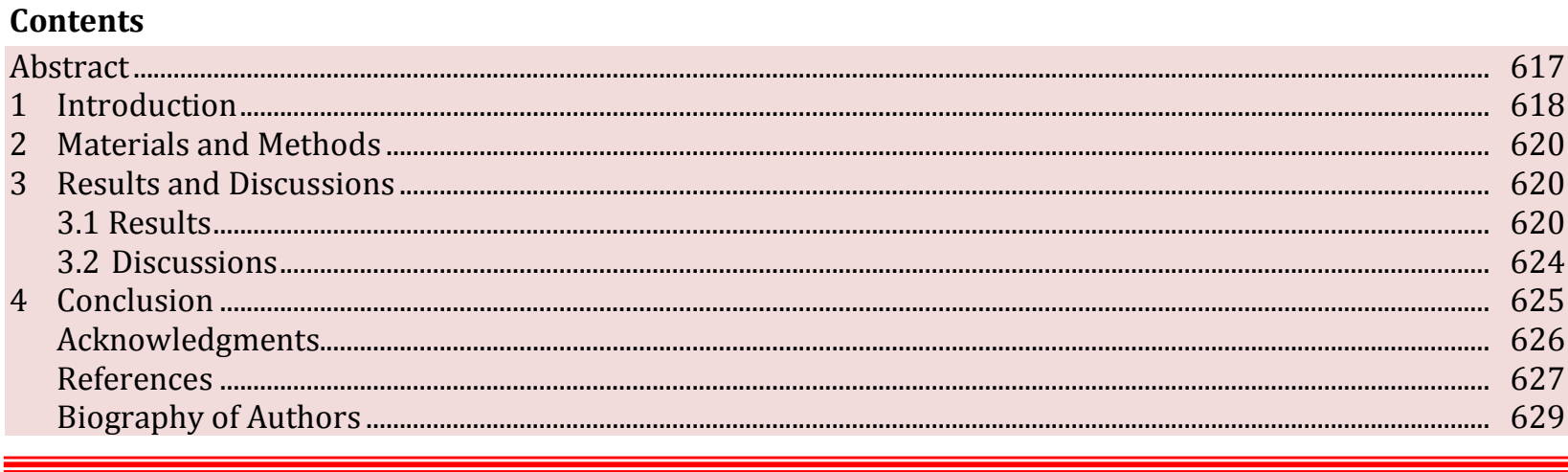

\section{Introduction}

Modernization of the educational system provides new opportunities and ways of updating educational information, however, at the same time, it puts forward increased requirements for the professional competence of the teacher. Modern information technologies provide virtually unlimited opportunities in the placement, storage, processing, and delivery of information at any distance and of any volume and content. Within these conditions, the pedagogical problems of organizing the educational process come to the fore in the further consideration of distance education. The objective of teaching a student who has professional knowledge in his sphere and can interact in a modern information society can only be solved by a teacher who can work in the field of mixed teaching methods - synchronous and asynchronous pedagogical technologies.

Modern educational systems in numerous countries are changing, modernizing, and increasingly resorting to the use of technologies providing students with more opportunities and prospects for successful learning. The application of synchronous and asynchronous teaching methods currently has the most comprehensive and direct impact on the content and forms of learning.

\section{Relevance research}

The sudden impact of the COVID-19 pandemic forced universities to provide students with conditions for online teaching and learning that were immediately applicable and, consequently, they established a new quality of learning. This has resulted in applying a wide variety of synchronous and asynchronous online teaching and learning settings (Callejas et al., 2004; Lawrence et al., 2004). On this basis, some HEIs have balanced both types, while others have offered either predominantly synchronous or asynchronous teaching and learning methods (Roga et al., 2015; Ramísio et al., 2019). Consequently, understanding the importance of the combined action of synchronous and asynchronous teaching methods in the HEIs will make it possible to achieve maximum educational results in the context of modernizing the educational system following the requirements of the pandemic (Underhill, 2006; Sundli, 2007).

The world has witnessed an outbreak of coronavirus $(2019-\mathrm{nCoV})$ with quarantine restrictions. To ensure the continuity of teaching and learning in this new provision of urgent distance education, alternative approaches have been adopted in the form of synchronous and asynchronous methods (Swaran et al., 2021; Bakhtiyorovna, 2021). According to the viewpoint of Zounek et al. (2020), digital technologies have become an important part of the educational policy of most European countries. Their implementation in the teaching and learning process implies a significant potential for encouraging or initiating changes in the field of education (Mak et al., 1999; Thai et al., 2017). It can be argued (Pech et al., 2021), that in the educational policies of countries, there is a noticeable shift away from the features of traditional pedagogy with an emphasis on the development of the skill-based component of learning, including on key competencies. The investigation conducted by Etchells et al. (2020), describes the physical and psychological consequences of the movement and functioning of students of higher educational institutions in the virtual world that teachers and students now deal with. Besser et al. (2020), and Lee \& Winandy (2021), have investigated the link between changes in psychological stress levels and vocal symptoms among the teachers of Israeli academic colleges 
who needed to switch to synchronized online teaching during the global COVID-19 pandemic (Kusumajaya, 2021; Widana et al., 2021).

The closure of educational events in the Kingdom of Saudi Arabia due to the ongoing COVID-19 pandemic has led to an unplanned shift from traditional teaching to a system providing exclusively digital teaching and learning (Khalil et al., 2020). The mixed synchronous regime of teaching and learning is gaining popularity in higher educational institutions, while its impact on the experience of students and teachers has not been studied yet. Few studies have been conducted to contextualize the effects of teaching and learning within the conditions of this teaching and learning model (Szeto, 2014; Attamimi et al., 2020).

There are numerous problems in determining the comparative effectiveness of synchronous and asynchronous techniques (Schiff et al., 2021). The purpose of Tiburcio's (2021), investigation was to identify the degree of technological integration of teachers into synchronous and asynchronous learning models, which made it possible to determine the least mastered skills in basic computer problem solving and Google programs often used in online synchronous and asynchronous learning (Velázquez et al., 2021). SOA technology, according to the point of view of $\mathrm{Qu}$ (2018), can connect various service functions of the application through a well-defined interface, and then form a distributed system through an appropriate management process. SOA-based simulation and synchronous learning system can provide the advantage of dexterity and high efficiency of this technology; consequently, its practical value is high.

Asynchronous learning is a key feature of successful online learning programs. Asynchronous learning provides flexibility for students. It easily comprises different learning styles given the fact that students often can "choose their adventure", when it comes to the order, they want to cover the material and immerse themselves deeply in a particular topic. Asynchronous learning is often referred to as independent learning forasmuch as students can get access to the course from anywhere in the world via the Internet. Asynchronous learning uses other tools and systems so that the instructor and students can interact according to their schedules (Bueno, 2020; Kistan et al., 2020).

Seifert (2019), explores methods for implementing synchronous teaching among teachers and students and discusses the importance of training teachers working with these tools. In addition, the authors develop the planning of synchronous learning and teaching in various online environments for different purposes and the formation of the synchronous learning space. The results are used to clarify how to provide an optimal student-centered environment on synchronous online learning platforms. Recognizing the advantages/disadvantages of synchronous learning and its contribution can help make optimal use of these tools when planning to learn. Facilitators choose various teaching technologies and methods for the development and moderation of learning activities. These are just some of the decisions influencing the role of teachers and administrators. Because the technologies used by teachers are evolving, permanent investigations can help understand the teacher's role in distance education. Despite a significant number of the provisions under consideration, the issue of interacting systems of methods of synchrony and asynchrony in the modern pedagogy of HEIs remains unexplored.

Aims

lies in determining the ratio of synchronous and asynchronous teaching and learning methods in modern pedagogy on the example of the analysis of the HEIs' activities within the conditions of quarantine restrictions.

The research objectives are as follows:

- to conduct a sociological survey of teachers and students of the higher educational institutions;

- to find out the criterion for the allocation if the importance concerning choosing one of the proposed (or both proposed methods);

- to provide guidelines for aligning the equivalence indicator of synchronous and asynchronous training methods.

Lytvyn, V., Akimova, O., Kuznetsova, H., Zenchenko, T., Stepanenko, O., \& Koreneva, I. (2021). The use of synchronous and asynchronous teaching methods in pedagogical education in COVID-19 terms. International Journal of Health Sciences, 5(3), 617-629. https://doi.org/10.53730/ijhs.v5n3.2681 


\section{Materials and Methods}

The research was conducted in two stages. The first stage lasted three months - July - September 2021, and it was like the information collection stage. The second stage lasted one month - October 2021, and was analytical. A sociological survey of 1750 teachers and 3681 students of HEIs was chosen as the main method of the first research stage. They had to answer the questions, according to the results of which the authors identified a criterion for the allocation of the importance concerning choosing one of the proposed (or both proposed methods). Analytics (processing of results) was chosen as the main method of the second stage of the research). The stage of collecting information is organized online by sending a questionnaire created on the Google forms platform to the e-mails of the participants. The information analysis stage involved the automatic generation of respondents' answers in the table. Further processing concerned the automatic calculation of the responses' percentage and the number of participants.

\section{Results and Discussions}

\subsection{Results}

The survey consisted of thematic blocks (separately for teachers, separately for students), in each of which the respondents had to rank the categories offered to them.

1a. Identify the benefits of synchronous learning (students' opinion). From among the proposed benefits (easy interaction; real-time mode; questioning, instant answers, motivation, and help), respondents have singled out the order of importance in the way of ranking. The results and the legend graphic are represented in Figure 1.

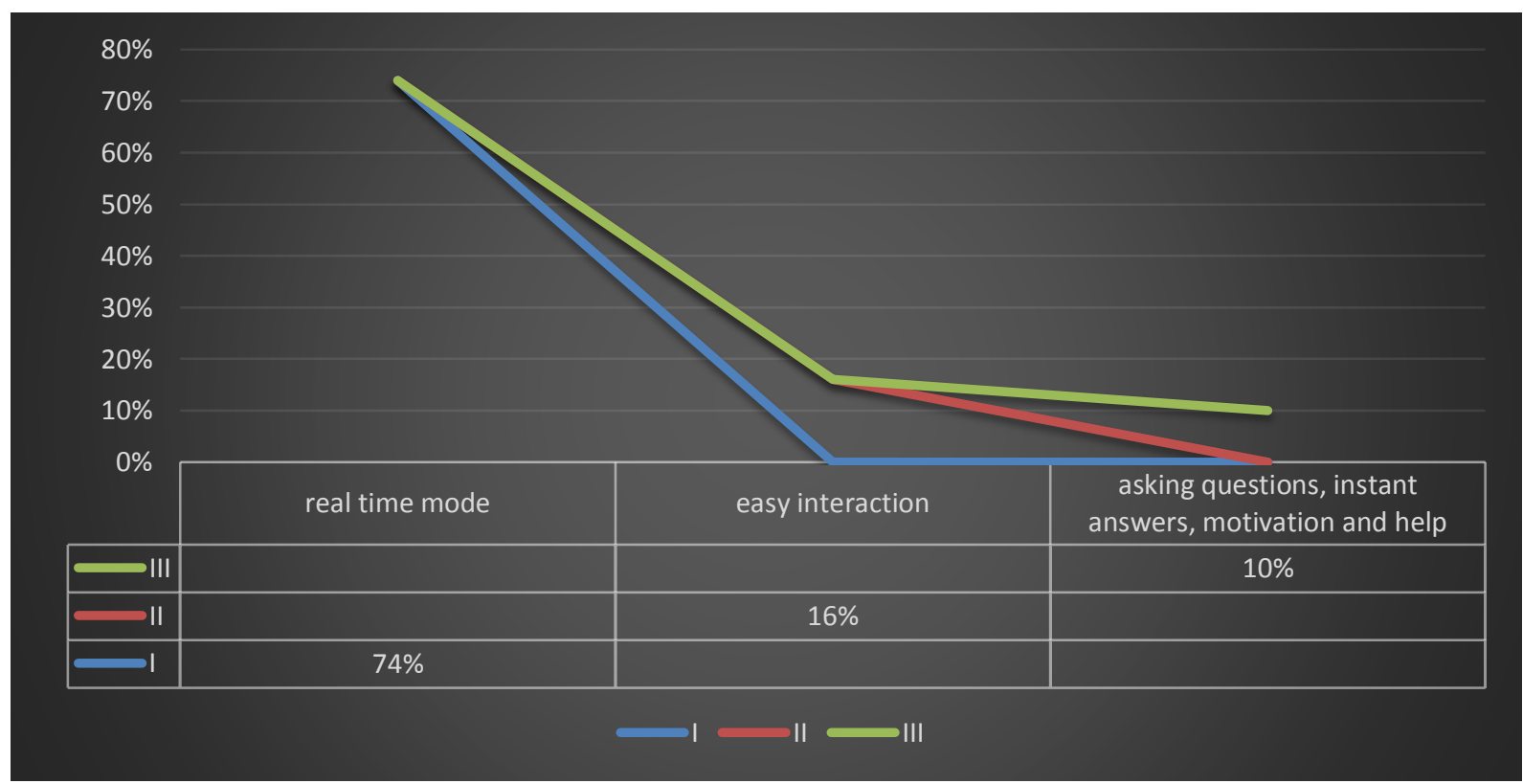

Figure 1. Advantages of synchronous learning for students in terms of COVID-19

The figure has been compiled based on the table of results of answers

1b. Identify the benefits of synchronous learning (for teachers). From among the proposed benefits (immediate feedback from the teacher, group classes, high concentration), respondents have identified the order of importance in the way of ranking. The results and the legend graphic are represented in Figure 2. 


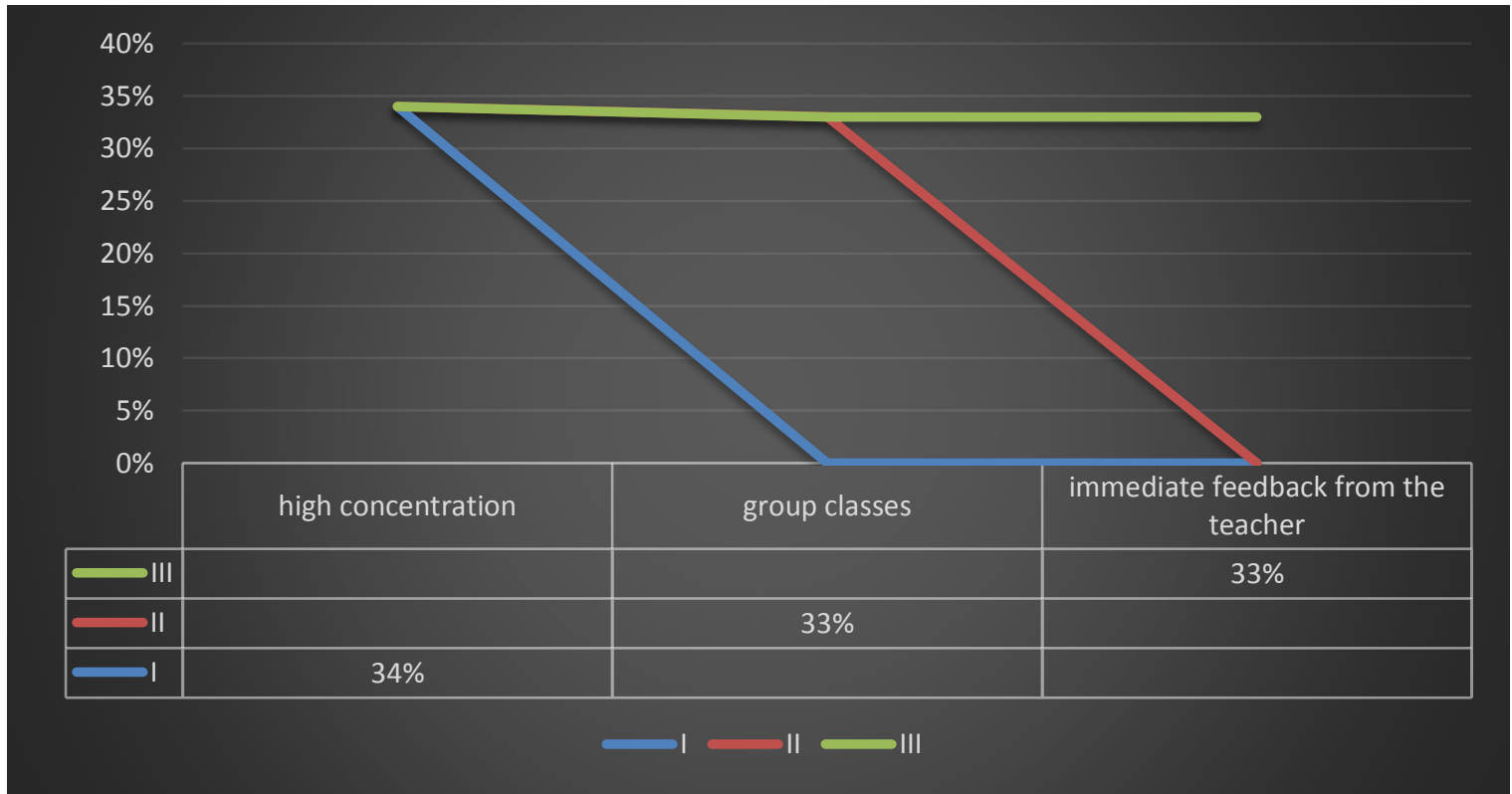

Figure 2. Advantages of synchronous learning for teachers in terms of COVID-19

The figure has been compiled based on the table of results of answers

2b. Identify the drawbacks of synchronous learning (students). From among the proposed drawbacks (physical compliance with the schedule, poor implementation of individualization, appropriate training), the respondents have singled out the order of importance in the method of ranking. The results and the legend graphic are represented in Figure 3.

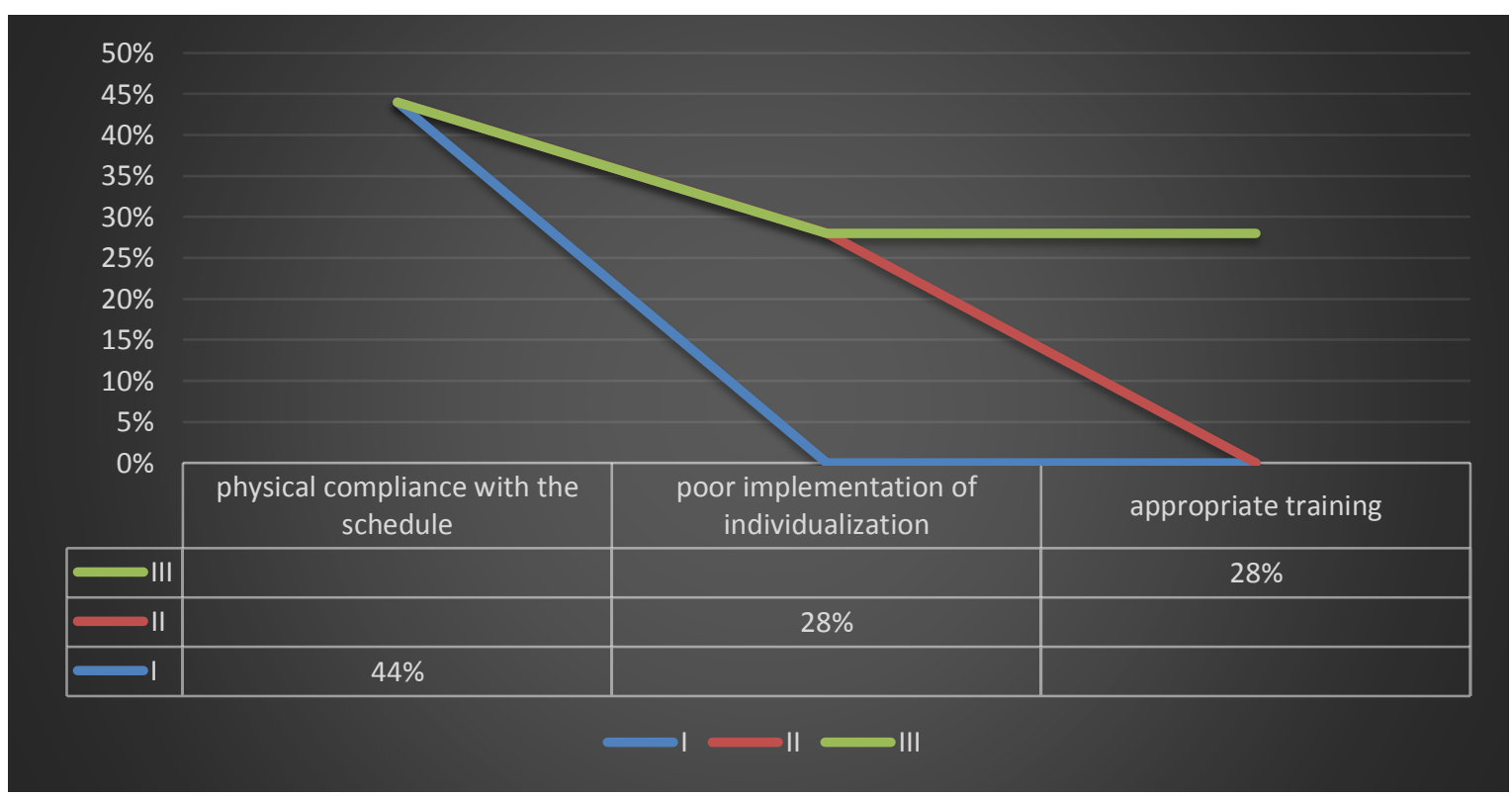

Figure 3. Disadvantages of synchronous learning for students in terms of COVID-19

The figure has been compiled based on the table of results of answers

Lytvyn, V., Akimova, O., Kuznetsova, H., Zenchenko, T., Stepanenko, O., \& Koreneva, I. (2021). The use of synchronous and asynchronous teaching methods in pedagogical education in COVID-19 terms. International Journal of Health Sciences, 5(3), 617-629. https://doi.org/10.53730/ijhs.v5n3.2681 
3a. Identify the drawbacks of synchronous learning (teachers). From among the proposed drawbacks (weak content of the digital learning platform, poor organization of various communication channels, low level of digital alternative), the respondents have singled out the order of importance in the way of ranking. The results and the legend graphic are represented in Figure 4.

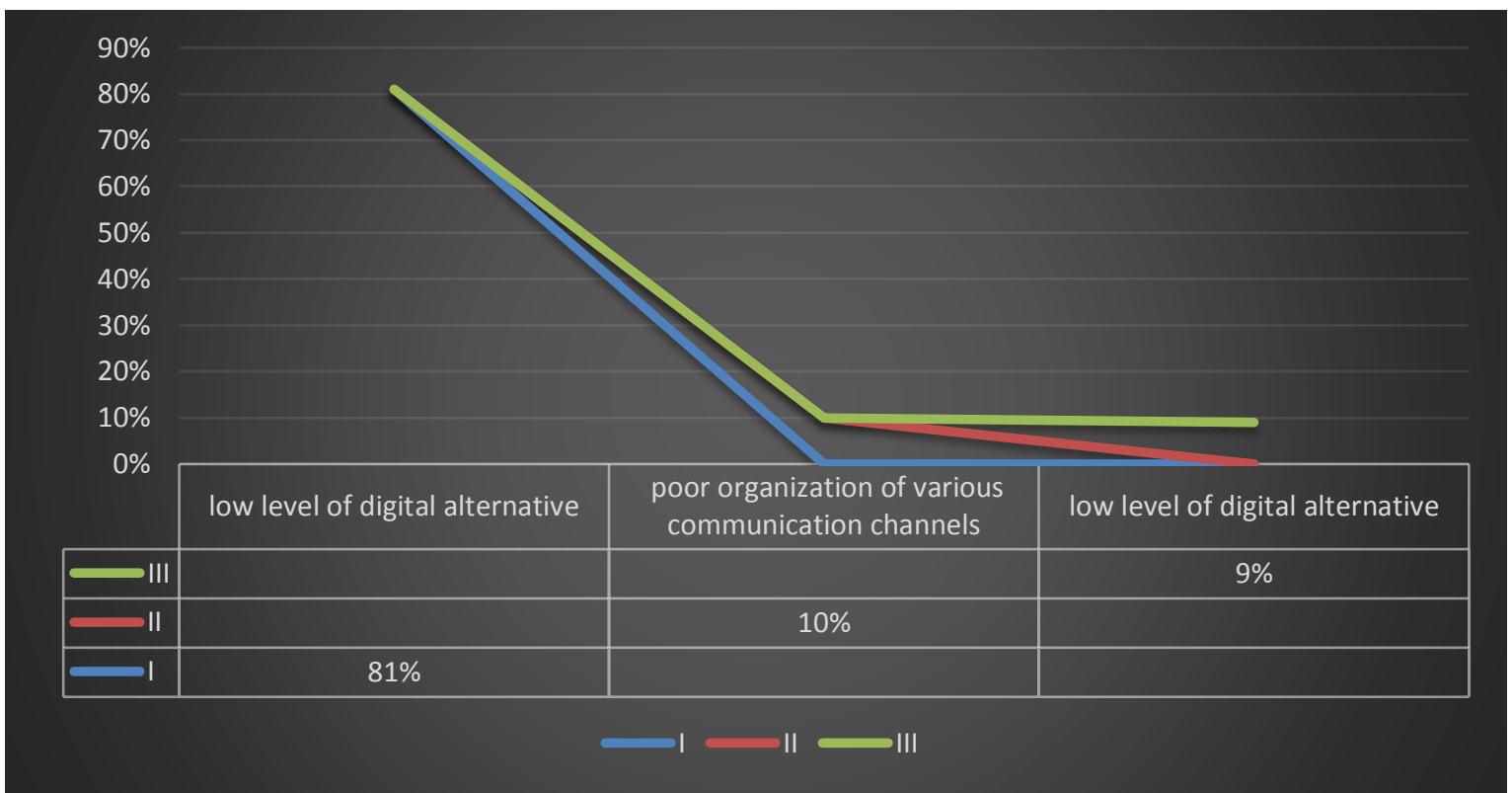

Figure 4. Disadvantages of synchronous learning for teachers in terms of COVID-19

The figure has been compiled based on the table of results of answers

4a. Identify the benefits of asynchronous learning (students' opinion). From among the proposed benefits (flexibility, anti-localization, cost-effectiveness, time mobility), the respondents have singled out the order of importance in the ranking method. The results and the legend graphic are represented in Figure 5.

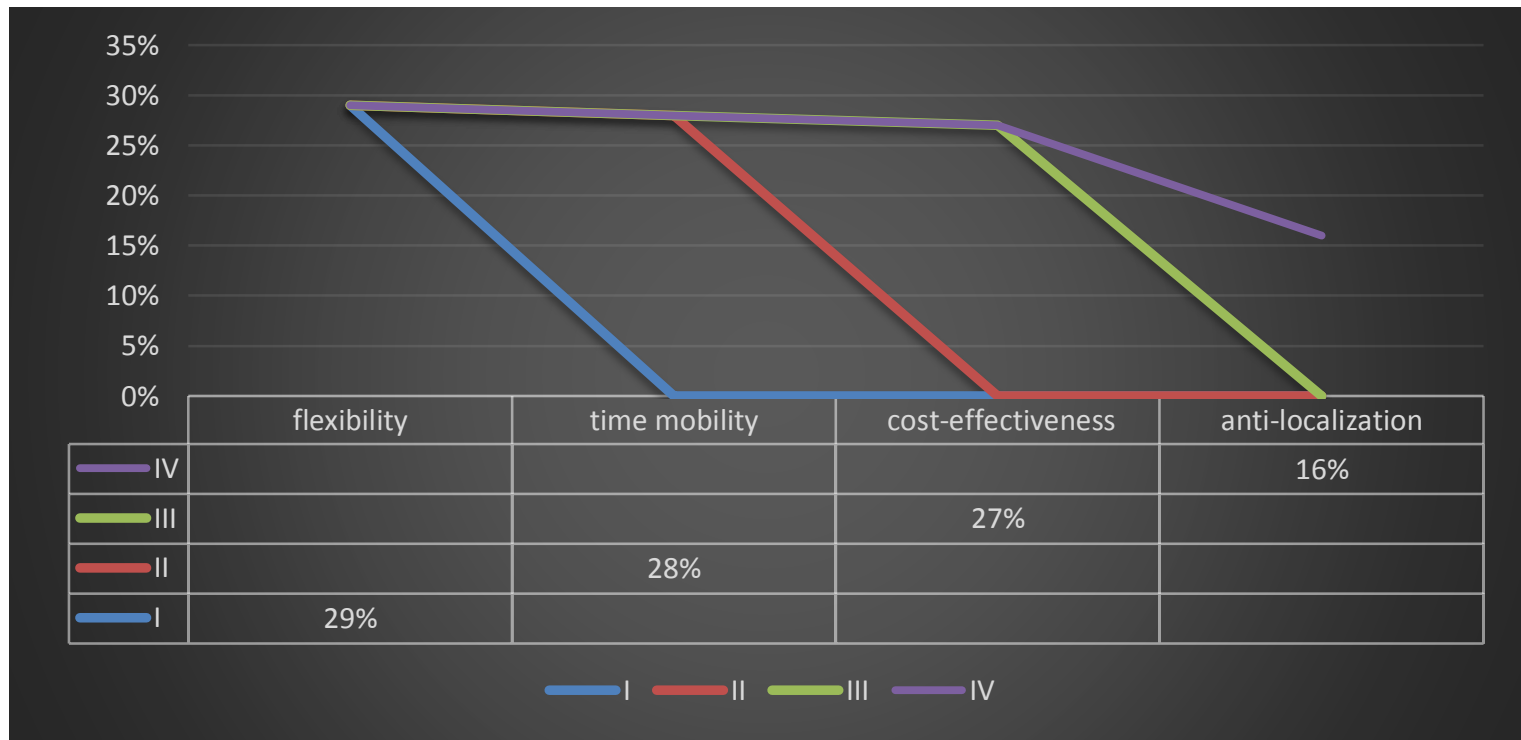

Figure 5. Advantages of asynchronous learning for students in terms of COVID-19

Figure has been compiled based on the table of results of answers 
4b. Identify the benefits of asynchronous learning (teachers' opinion). From among the proposed benefits (one's own pace of work, the schedule convenience, point definition of the purposes) respondents have singled out the order of importance in a way of ranking. The results and the legend graphic are represented in Figure 6.

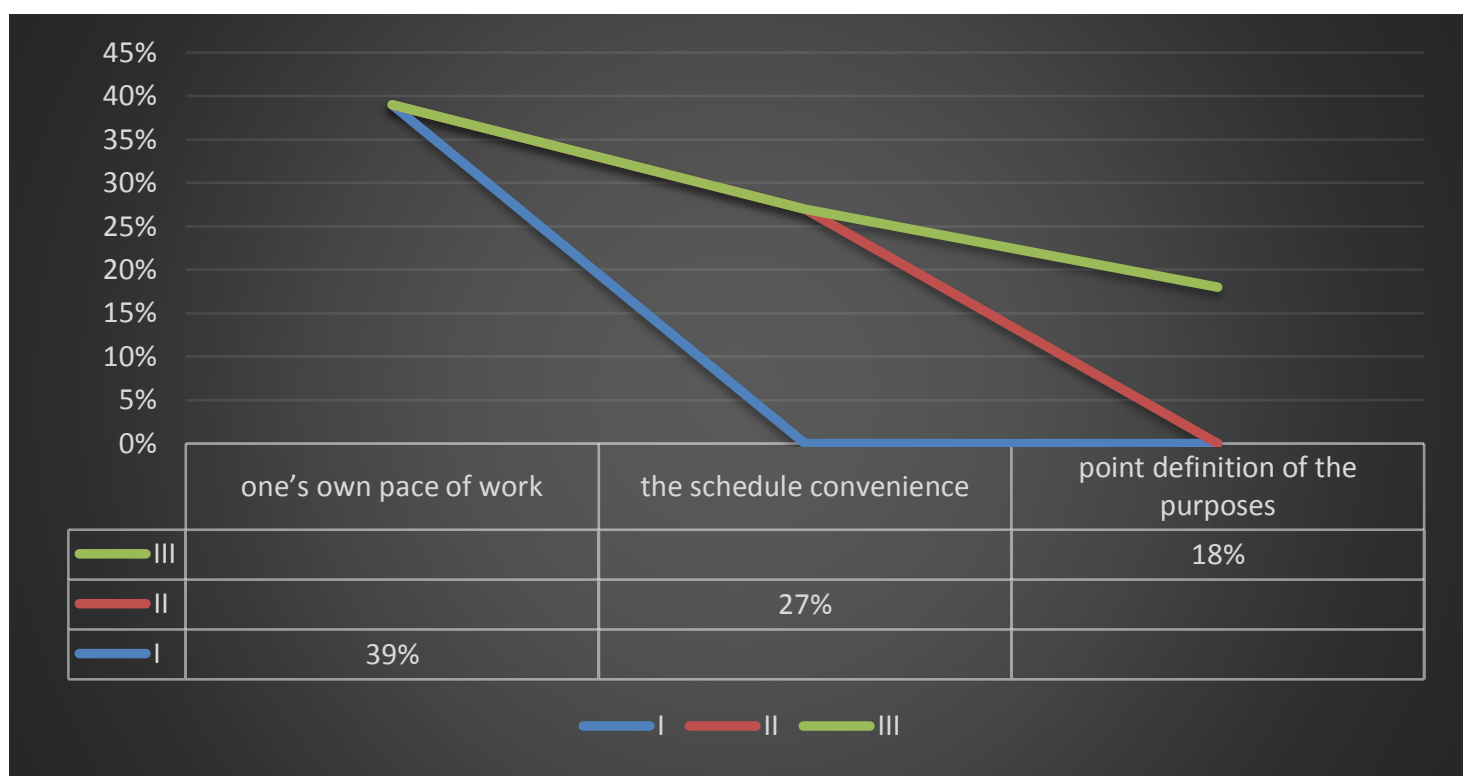

Figure 6. Advantages of asynchronous learning for teachers in terms of COVID-19

Figure has been compiled based on the table of results of answers

5a. Identify the drawbacks of asynchronous learning (students' opinion). Among the proposed drawbacks (limitation of contact, isolation, the need for self-discipline), respondents have singled out the order of importance in the method of ranking. The results and the legend graphic are represented in Figure 7.

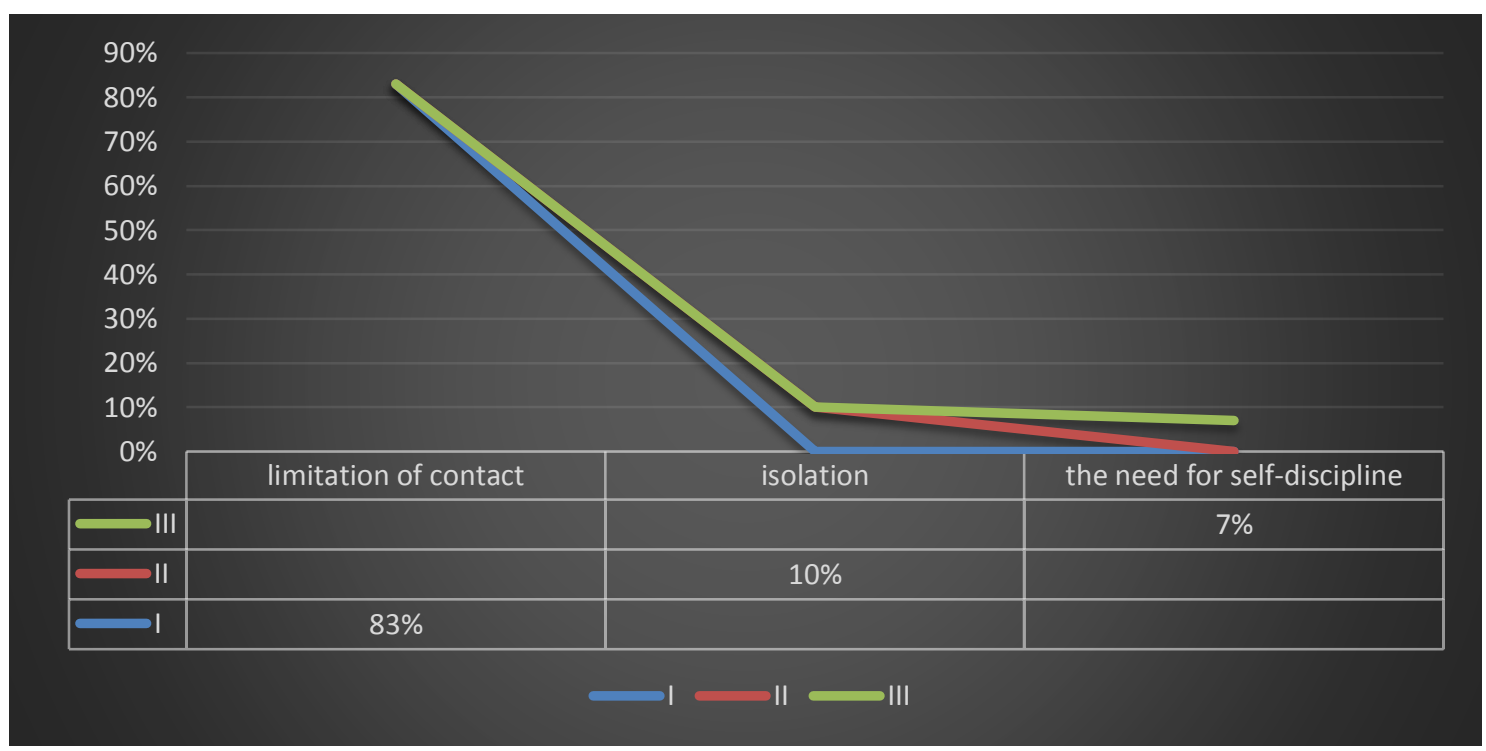

Figure 7. Disadvantages of asynchronous learning for students in terms of COVID-19

The figure has been compiled based on the table of results of answers

Lytvyn, V., Akimova, O., Kuznetsova, H., Zenchenko, T., Stepanenko, O., \& Koreneva, I. (2021). The use of synchronous and asynchronous teaching methods in pedagogical education in COVID-19 terms. International Journal of Health Sciences, 5(3), 617-629. https://doi.org/10.53730/ijhs.v5n3.2681 
5a. Identify the drawbacks of asynchronous learning (teachers' opinion). From among the proposed drawbacks (decrease in an academic discipline, decrease in socialization, the severity of feedback), respondents have singled out the order of importance in the way of ranking. The results and the legend graphic are represented in Figure 8.

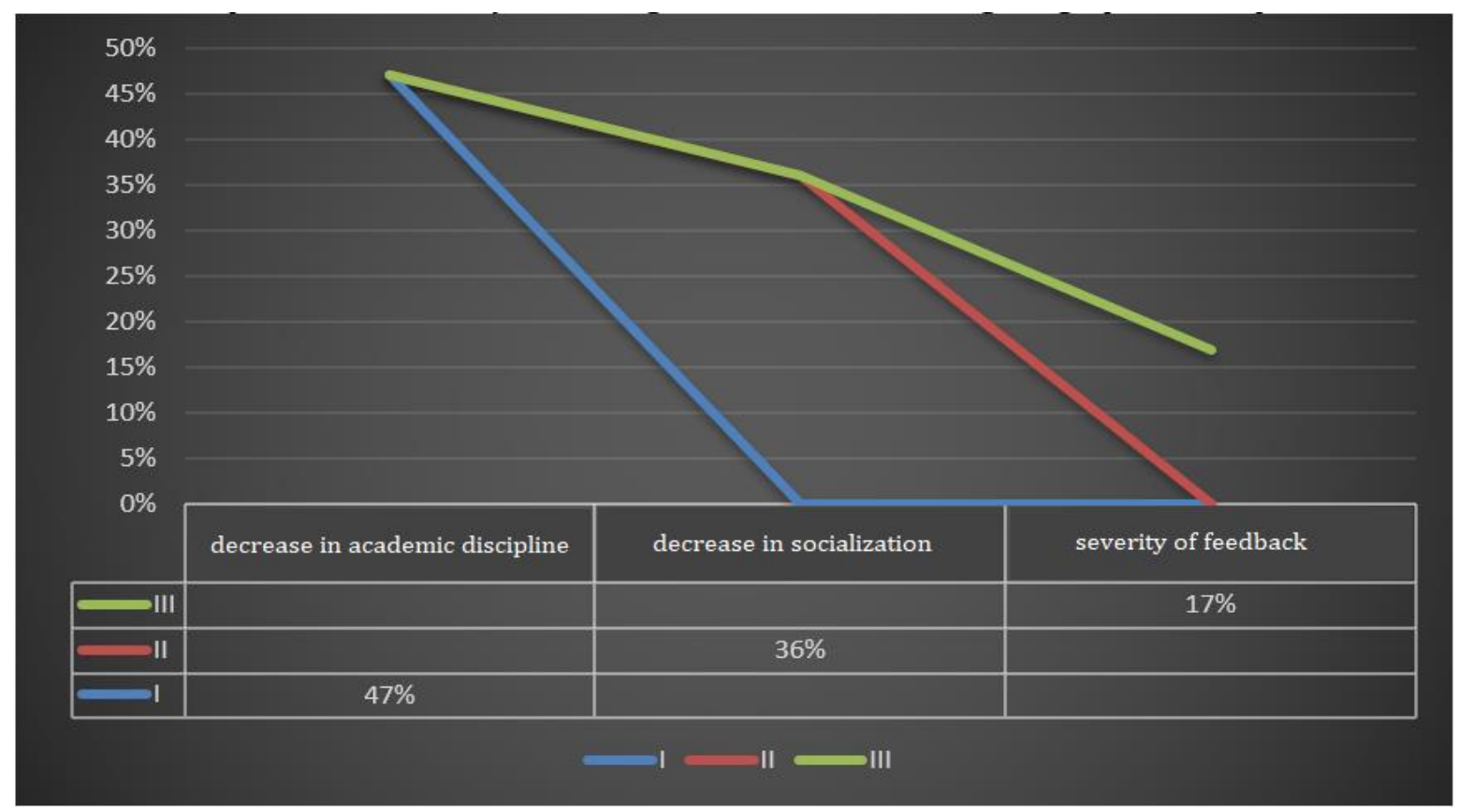

Figure 8. Disadvantages of asynchronous learning for teachers in terms of COVID-19

The figure has been compiled based on the table of results of answers

Therefore, summarizing the results, it is clear that the ratio of synchronous and asynchronous teaching methods in modern pedagogy, using the example of the analysis of the activity of the HEIs within the conditions of quarantine restrictions, is arranged in links 15:13.

\subsection{Discussions}

The study conducted by Yang (2019), has revealed that it is necessary to compare the changes in the asynchronous teaching method and the traditional teaching method. The construction of heterogeneous study groups is divided according to the principles of intergroup homogeneity and intragroup heterogeneity. After the semester of study, it has been established that the experimental group (asynchronous teaching method) compared to the control group (traditional teaching method) has the indicators as follows: 1) there are no basic basketball skills, however, there is a significant difference in $\mathrm{V}$-word dribbling scores $(\mathrm{p}<0,05)$, and there is a very significant difference in turning behavior $(p<0,01) ; 3)$ there is a significant difference in learning motivation $(\mathrm{p}<0,05)$, and there is a very significant difference in interest in learning and attitudes towards learning $(p<0,01)$. The results of the investigation of Shieh \& Qiang-Jun, (2020), have found a positive interrelationship between 1 . synchronous learning motivation and learning online, 2 . learning motivation and learning outcomes, and 3. Internet synchronous learning outcomes.

According to the viewpoint of McCann (2021), online lecture materials have been structured to help students develop critical thinking, soft skills such as responsibility and teamwork. The tasks were designed to promote learning in the team, which also helped reduce feelings of isolation and increase motivation. Students participated in weekly discussion boards, where they published lecture notes and answered comments and questions through intensive conversations. These discussions improved metacognitive skills, encouraged connection with the material, fostered strong annotation skills, and helped build community. An obstacle to 
teaching an asynchronous science course online is the laboratory part. The goal lies in making the online lab as close as possible to tangible lab work and matching the lecture material while maintaining a user-friendly interface. To teach students to understand rocks and minerals, a sample video was created to help them get acquainted with the identification scheme. A weathering laboratory was developed that used sand samples from all over the world, different environments with various features. These laboratory activities practically provided the students with the appropriate samples at no extra cost. Summarizing, it should be noted that to help students explore core competencies in geology and think critically, the query-based curriculum, typically taught during laboratory activities, has been moved to the asynchronous online course. To perform laboratory tasks, students used free online resources, supplementing the materials with pre-recorded video demonstrations of laboratory activities. Section rooms were used to facilitate small group discussions, as well as to help students gain the material for encouraging self-knowledge (McCann, 2021; Sztekler \& Jodłowski, 2017).

Fabriz et al. (2021), have found out whether the predominance of synchronous or asynchronous teaching and learning in higher educational institutions is related to the specific experience and results of students in Germany. Researchers have analyzed the extent to which these two types of teaching and learning environments support the basic psychological needs of students in autonomy, competence, and kinship proposed by the self-determination theory (SDT). Data were collected after the first online semester because of the COVID-19 pandemic. The results point to the fact that from students' perspective, teaching methods differ in their potential in supporting social interaction and maintaining the basic psychological needs suggested by the SDT. Students who had studied predominantly in synchronous conditions reported on more peer-focused activities, such as feedback, compared with students who had been predominantly in asynchronous conditions. On the contrary, teachers perceive smaller differences between teaching methods in synchronous and asynchronous conditions, especially about feedback activities. Along with this, students, living predominantly synchronously, have reported greater support for their basic psychological needs in maintaining competence and connectivity, as well as greater overall satisfaction with the online term compared to students who have mostly worked with asynchronous methods. All students have experienced better satisfaction of psychological needs and acceptance of higher technology which has coincided with more favorable outcomes.

According to observations of Charidimou et al. (2020), AUTh has been expanding its innovations in the fields of e-learning and distance learning in recent years. Information Technology Center (ITC) and Office of Science and Technology Support (AATSO) provide holistic solutions in the above areas. These capabilities are constantly being improved, making distance education a more authentic process and providing training to users anywhere and anytime. AATSO develops, accepts, and manages rich local environments along with the collaboration of tools and platforms, open or commercial ones. This equipment offers great potential for collaboration with synchronous and asynchronous data transmission, powerful interactivity through learning flexibility, great new features, and options. Despite all the above, there is still an understanding that no consensus is achieved on the interaction of synchronous and asynchronous learning, giving rise to scientific discussions in the future.

\section{Conclusion}

Therefore, to equalize the equivalence indicator of synchronous and asynchronous teaching methods, the authors recommend the teachers to adhere to the basic ideas as follows:

- to create a hypertext structure, thereby combining the theoretical material on the subject into a presented, logical structure;

- to create a software package that allows students independently control the quality and completeness of knowledge acquisition;

- to create a set of test tasks that provide the opportunity for the teacher to assess the completeness of the theoretical knowledge gained;

- to establish levels of high technical characteristics of the equipment being used;

- to evaluate the free time of the teacher and students;

Lytvyn, V., Akimova, O., Kuznetsova, H., Zenchenko, T., Stepanenko, O., \& Koreneva, I. (2021). The use of synchronous and asynchronous teaching methods in pedagogical education in COVID-19 terms. International

Journal of Health Sciences, 5(3), 617-629. https://doi.org/10.53730/ijhs.v5n3.2681 
- to use a virtual simulation of communication;

- to establish independence from the time of communication.

An important direction of further scientific investigations will be the definition of synchronous and asynchronous interactions between participants in educational activities at the international level. The practical significance of the research was to provide recommendations for leveling the equivalence indicator between synchronous and asynchronous teaching and learning methods.

Acknowledgments

We are grateful to two anonymous reviewers for their valuable comments on the earlier version of this paper. 


\section{References}

Attamimi, H. R. ., Lestari, Y. ., Situmorang, B. . H. L. ., Antari, G. Y. ., \& Nugrawati, N. . (2020). Application of habituation method in germas interventionsin: the pandemic time COVID-19. International Journal of Health \& Medical Sciences, 3(1), 98-104.

Bakhtiyorovna, K. N. (2021). Interactive teaching methods: Critical thinking. Academicia: An International Multidisciplinary Research Journal, 11(1), 1163-1167.

Besser, A., Lotem, S., \& Zeigler-Hill, V. (2020). Psychological stress and vocal symptoms among university professors in Israel: implications of the shift to online synchronous teaching during the COVID-19 pandemic. Journal of Voice. https://doi.org/10.1016/j.jvoice.2020.05.028

Bueno, D. C. (2020). G-SPACE's guidance on asynchronous teaching and learning via Google Classroom. April), $0-24$.

Callejas, A., Lupiánez, J., \& Tudela, P. (2004). The three attentional networks: On their independence and interactions. Brain and cognition, 54(3), 225-227. https://doi.org/10.1016/j.bandc.2004.02.012

Charidimou, D., Politis, D., \& Aleksić, V. (2020). Multilingual Conversational Communication Tools for Distance Learning.

Etchells, M. J., Brannen, L., Donop, J., Bielefeldt, J., Singer, E. A., Moorhead, E., \& Walderon, T. (2020). Synchronous Teaching: Asynchronous Trauma.

Fabriz, S., Mendzheritskaya, J., \& Stehle, S. (2021). Impact of Synchronous and Asynchronous Settings of Online Teaching and Learning in Higher Education on Students' Learning Experience During COVID-19. Frontiers in Psychology, 12.

Khalil, R., Mansour, A. E., Fadda, W. A., Almisnid, K., Aldamegh, M., Al-Nafeesah, A., ... \& Al-Wutayd, O. (2020). The sudden transition to synchronized online learning during the COVID-19 pandemic in Saudi Arabia: a qualitative study exploring medical students' perspectives. BMC medical education, 20(1), 1-10.

Kistan, K., Malka, S., \& Musni, M. (2020). The relationship between knowledge, attitude, and readiness of academic community in Covid-19 spread prevention: Batari Toja Nursing Academy, Watampone. International Journal of Health \& Medical Sciences, 3(1), 72-78.

Kusumajaya, A. A. N. (2021). Individual and social environmental factor as risk factor of BMI-for-age in school children. International Journal of Health Sciences, 5(2), 89-98. https://doi.org/10.29332/ijhs.v5n2.1242

Lawrence, V. A., Hazuda, H. P., Cornell, J. E., Pederson, T., Bradshaw, P. T., Mulrow, C. D., \& Page, C. P. (2004). Functional independence after major abdominal surgery in the elderly. Journal of the American College of Surgeons, 199(5), 762-772. https://doi.org/10.1016/j.jamcollsurg.2004.05.280

Lee, S. Y., \& Winandy, J. (2021). Scientization of professional teacher knowledges and construction of teaching methods. Paedagogica Historica, 1-18.

Mak, A. S., Westwood, M. J., Ishiyama, F. I., \& Barker, M. C. (1999). Optimising conditions for learning sociocultural competencies for success. International journal of intercultural Relations, 23(1), 77-90. https://doi.org/10.1016/S0147-1767(98)00026-1

McCann, V. (2021). Synchronous and asynchronous teaching innovations for online introductory geoscience lab courses during covid-19. Joint 55th Annual North-Central / 55th Annual South-Central Section Meeting . 18, 3-5.

Pech, M., Rehor, P., \& Slabová, M. (2021). Students Preferences in Teaching Methods of Entrepreneurship Education. Journal on Efficiency and Responsibility in Education and Science, 14(2), 66-78.

$\mathrm{Qu}$, P. (2018). Multimedia Teaching Platform Construction for Fashion Design Based on Simulation and Synchronous Teaching System. International Journal of Emerging Technologies in Learning, 13(5).

Ramísio, P. J., Pinto, L. M. C., Gouveia, N., Costa, H., \& Arezes, D. (2019). Sustainability Strategy in Higher Education Institutions: Lessons learned from a nine-year case study. Journal of Cleaner Production, 222, 300-309. https://doi.org/10.1016/j.jclepro.2019.02.257

Roga, R., Lapina, I., \& Müürsepp, P. (2015). Internationalization of higher education: Analysis of factors influencing foreign students' choice of higher education institution. Procedia-Social and Behavioral Sciences, 213, 925-930. https://doi.org/10.1016/j.sbspro.2015.11.506

Schiff, M., Zasiekina, L., Pat-Horenczyk, R., \& Benbenishty, R. (2021). COVID-related functional difficulties and concerns among university students during COVID-19 pandemic: A binational perspective. Journal of community health, 46(4), 667-675.

Lytvyn, V., Akimova, O., Kuznetsova, H., Zenchenko, T., Stepanenko, O., \& Koreneva, I. (2021). The use of synchronous and asynchronous teaching methods in pedagogical education in COVID-19 terms. International Journal of Health Sciences, 5(3), 617-629. https://doi.org/10.53730/ijhs.v5n3.2681 
Seifert, T. (2019). Improving involvement through interaction in synchronous teaching/learning in higher education. In Educational Technology and Resources for Synchronous Learning in Higher Education (pp. 229-254). IGI Global.

Shieh, C. J., \& Qiang-Jun, Q. I. (2020). An Integration of Internet IPR Synchronous Teaching on Learning Outcomes. Revista de Cercetare si Interventie Sociala, 69, 194.

Sundli, L. (2007). Mentoring-A new mantra for education?. Teaching and teacher education, 23(2), 201-214. https://doi.org/10.1016/j.tate.2006.04.016

Swaran Singh, C., et al. (2021). Using Synchronous vs. Asynchronous Methods during the COVID-19 Pandemic in Malaysia: Preservice and In-Service Teachers' Perspectives, 5, 18-21.

Szeto, E. (2014). A comparison of online/face-to-face students' and instructor's experiences: Examining blended synchronous learning effects. Procedia-Social and Behavioral Sciences, 116, 4250-4254. https://doi.org/10.1016/j.sbspro.2014.01.926

Sztekler, K., \& Jodłowski, G. S. (2017). Case Teaching Method-New Teaching Method At Technical Universities. In Conference: 10th annual International Conference of Education, Research and Innovation, DOI (Vol. 10).

Thai, N. T. T., De Wever, B., \& Valcke, M. (2017). The impact of a flipped classroom design on learning performance in higher education: Looking for the best "blend" of lectures and guiding questions with feedback. Computers \& Education, 107, 113-126. https://doi.org/10.1016/j.compedu.2017.01.003

Tiburcio, J. M. (2021). Leveraging Technology in Asynchronous and Synchronous Teaching. Leveraging Technology in Asynchronous and Synchronous Teaching, 80(1), 16-16.

Underhill, C. M. (2006). The effectiveness of mentoring programs in corporate settings: A meta-analytical review of the literature.Journal of vocational behavior, 68(2), 292-307. https://doi.org/10.1016/j.jvb.2005.05.003

Velázquez, M. del R. H., Báez, A. A. L., Pérez, A. M., \& Luna, A. A. (2021). Educational innovation in the comprehensive training of nursing graduates. International Journal of Health Sciences, 5(1), 20-28. https://doi.org/10.29332/ijhs.v5n1.700

Widana, I.K., Sumetri, N.W., Sutapa, I.K., Suryasa, W. (2021). Anthropometric measures for better cardiovascular and musculoskeletal health. Computer Applications in Engineering Education, 29(3), 550561. https://doi.org/10.1002/cae.22202

Yang, Y. (2019, October). Application of asynchronous teaching method in College Basketball Course. In 4th International Conference on Modern Management, Education Technology and Social Science (MMETSS 2019) (pp. 348-351). Atlantis Press.

Zounek, J., Zaleska, K., \& Juhanak, L. (2020). Teaching with the use of ICT in an international perspective: on the way to modern pedagogy. Lifelong Learning - Lifelong Learning. 


\section{Biography of Authors}

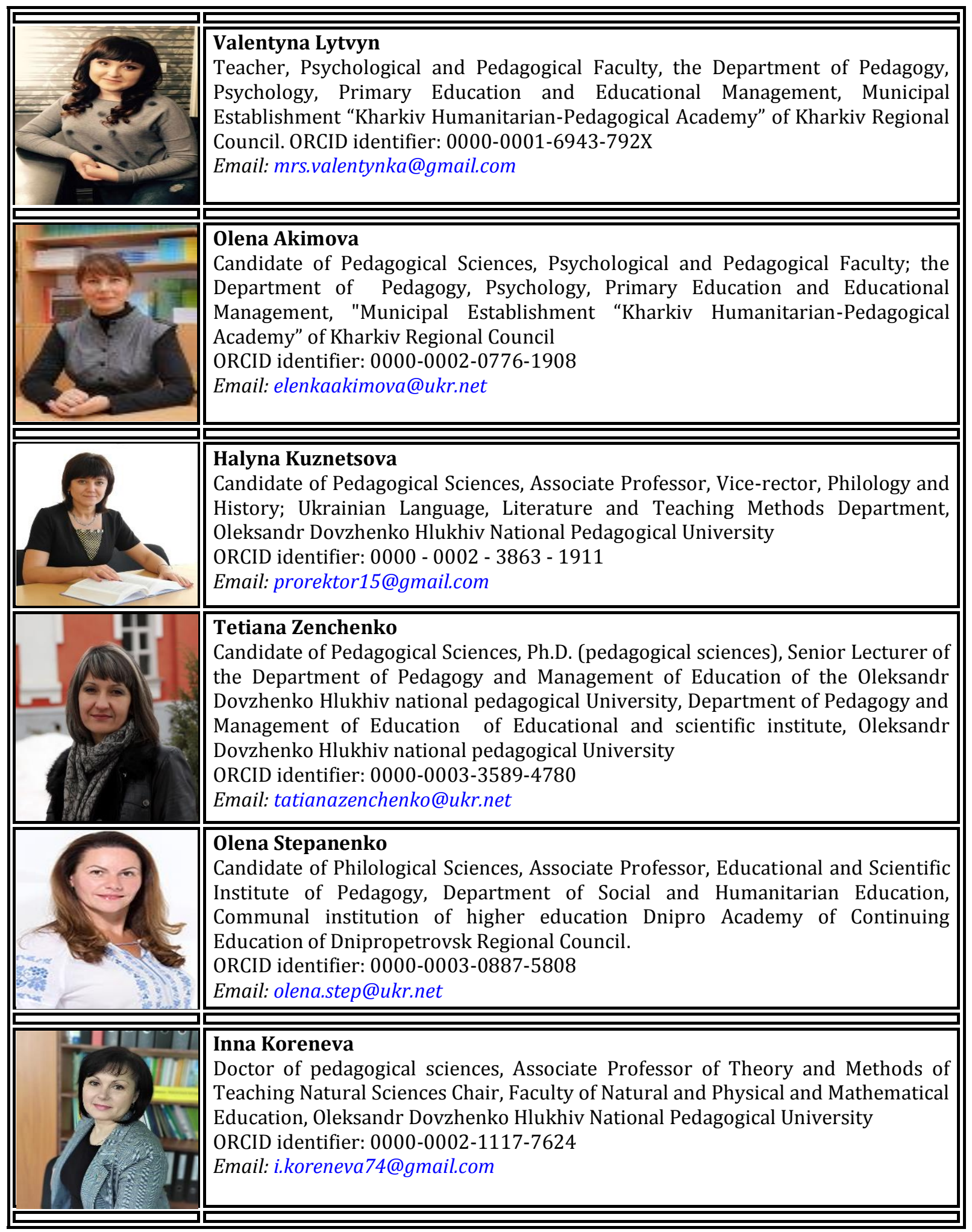

Lytvyn, V., Akimova, O., Kuznetsova, H., Zenchenko, T., Stepanenko, O., \& Koreneva, I. (2021). The use of synchronous and asynchronous teaching methods in pedagogical education in COVID-19 terms. International Journal of Health Sciences, 5(3), 617-629. https://doi.org/10.53730/ijhs.v5n3.2681 